\title{
SPACE IN THE AMBIENCE: IS AMBIENT MUSIC SOCIALLY RELEVANT?
}

\section{Ambrose Field}

Today, nearly every space that can be filled with digital content is filled with digital content. Even contemplative personal reflective time can now be digitally mediated. This is a different world from the one where the idea of 'ambient music' first emerged. In the 1970s and early 1980s, our 'ambient environment' featured no augmented reality overlays, fewer opportunities for distracted attention (unless they were deliberately sought out), and a vastly reduced need for personal multitasking. Then, fewer situations required a high degree of context switching to address incoming information from sources other than those which we have immersed ourselves in out of choice, and ambient music, as an idea, was born within those environmental and cognitive conditions. Now, new definitions of embodied cognition have demonstrated that our ambient environment is crucial for understanding the world through non-mediated forms of information, yet the idea initially behind much historical ambient music was one of inhabiting a space in our perception through which the un-mediated could be addressed. By defining historical ambient music as an 'information overlay' itself where a surrounding environment is displaced temporarily and overlaid with new information (as with an augmented reality), an alternative trajectory of development can be mapped out. Why do we now create specific environments for ambient music listening, rather than allowing ambient music itself the chance to occupy those situations? Has the embodiment brought about by increasing interaction in public ambient art, through technological processes, changed how we respond to artistic material embedded in our own day-to-day ambience? This chapter performs an experimental re-assembly of the situated components 
of ambient music, originally inherited from a pre-internet, pre-information society. It provides an assessment of the relevance of 'ambient' as an idea in a world where space in the ambience is already at a premium.

\section{Peripheral information and musical genre}

When we think of ambient, it is easy to imagine a type of time where what constitutes 'the present' feels fluid. In ambient time, seconds merge into perceivable moments and boundaries between the past and future dissolve. Today, information provision has ended this type of contemplative now, creating a feeling of the 'perceptual present'. ${ }^{1}$ Updates roll in and news feeds proliferate as live video and media from the world arrive at our personal devices. Meanwhile, a new sense of information richness in the perpetual present is changing definitions of the timescale and social reach ${ }^{2}$ of our ambient environment. If the framework behind the ambient environment has changed, then what has happened to the music? Has ambient music become aligned more to the past and the cultural values it grew up in, rather than the present? If so, should we seek to reassess the relationship between today's ambient environment and today's ambient music? ${ }^{3}$ I will explore this argument in three stages:

- Part one explores the notion of ambience as an environment, and examines existing models for describing soundscapes and listening processes;

- The second part of this chapter challenges the traditional approaches presented in part one by re-thinking ambience as a dynamic and personal quality, rather than as an environment to be observed.

1 Frederic Jameson argues that this information influx is ending a sense of history from a post-modernist perspective. Frederic Jameson, "Postmodernism and Consumer Society," in ed. Simon Malpas, Postmodern Debates (London: Macmillan Education UK, 2001), 22-36.

2 Defined here as the domain in which the ambient environment carries influence in our everyday lives.

3 This is done with a view to re-evaluating the perception of how ambient music fits within today's ambient information environment. This study is not a discussion surrounding changing public taste. 
Musical examples are given from artists seeking to engage with environmental sound in non-traditional ways;

- Thirdly, the idea is presented that ambient space is itself a nonlocated and embodied concept.

The aim of this chapter is to shift the focus of the discussion from the environment - a previous object of study for ambient music - to the people within it. In determining if there is space in the ambience today for ambient music we need to start by re-assessing the idea of the peripheral, as traditionally, peripheral surroundings play a large (but not exclusive) part in determining a sense of ambience. The word peripheral carries connotations of irrelevance ${ }^{4}$ together with a hierarchical discrimination between what is in the forefront of our attention and what falls outside of it. Such a description has a resonance with the positioning of early ambient genres as a type of music that could occupy both the background and foreground of attention. In doing so, a generic view that this music could be stateless and non-invasive began to emerge. ${ }^{5}$ Distilled by history, and re-purposed for commercial application, such ambient ideals from the 1970s have become lodged in the semiotics of ambient music genres which exist today. To provide this pervasive, stateless quality, the use of materials such as drones and long looped structures aided a growing perception that there was just one type of ambient music. Have the values from a traditional, common practice reading of 'peripheral' become genre-defining qualities?

Over time, an alignment between such stateless and non-invasive music, and the idea of minimalism, emerged. This proximity also makes it easy to perceive ambient music, as a genre, as being minimal or minimalist. However, such a reading is an artefact of a past time where what was considered to be

4 The Oxford English Dictionary includes 'Of secondary or minor importance; marginal' among the definitions.

5 Satie's Furniture Music as reviewed in Hervé Vanel, Triple entendre: Furniture music, muzak, muzak-plus (Illinois: University of Illinois Press, 2013). 
an 'ambient environment' functioned in a correspondingly simpler manner. Ambient today is not necessarily about minimalism (as a style rather than an aesthetic) but rather, our relationship with the environment. In associating minimalism with ambient music (both terms are used here in the most generic sense) we are dealing with a complex set of contradictions, resulting from overlaps between genres, artistic practices and methods. This chapter introduces ideas that challenge these dynamics in the light of contemporary theories of embodied cognition, the spatial self, and subjectcentred organisation. It is necessary to separate the concept of the ambient environment as an information system from the idea of ambient music as a genre. Having done this, we can trace the relative distance between these ideas through history, ending with the proposition that ambient music as a genre has diverged from how the ambient information environment operates today. Daniel Siepmann discusses the nature of interaction between environmental surroundings and music, demonstrating the fragility of the link between genre and environmental surroundings:

If we put on a record and then proceed to read or engage in other distracting activities, any music may easily be described as ambient, filling the space with sound that we seem to appreciate and enjoy, yet to which we are not quite listening. Thus, the idea of ambient music not only relies on the internal qualities of the music but also the utility that the music holds for the listener. ${ }^{6}$

To understand the human relationships and perceptual processes contained within what is broadly termed ambient music it is necessary first to break any assumed link between genre and environment. In Brian Eno's work, the qualities of site, place, and the actual ambience this music typically inhabits (either in reality or in our imagination) are those of a generalised

6 Daniel Siepmann, "A Slight Delay: Agency and Improvisation in the Ambient Sound World," Perspectives of New Music 48 no.1 (2010): 173-199. 
and homogeneous environment. For example, Ambient 1: Music for Airports $(1978)^{7}$ and Ambient 4: On Land (1982) ${ }^{8}$ : despite the titles, these pieces are not about specific locations. They function so well because they are non-prescriptive in location, thereby generating a space for the listener's imagination. Conceptual links emerge between the idea of environment as a mass and undifferentiated identity - tagged with a specific set of labels and characters - and the techniques and processes related to minimal musics. Whilst it might be convenient to align environmental sound and minimal music practices, the information systems underpinning minimal music design and environmental perception are not at all the same or even analogous. In the 1970s, ambient visual information displays, ambient audio display, and immersive technologies were present, but in their infancy. Personal ambient space - a factor which I will argue later is key to how we perceive ambient information - had a different relationship to public space than it does today. Today, ambience is filled with digital content on a significant level: even personal reflective time can be mediated by apps and the small details of daily existence - previously forgotten - can be monitored, logged and analysed as a global corpus of data (such as in digital health applications). Ambient information inhabits a new dimension of what I term the public data ambience', where local-scale personal source data is available to relatively few people, yet the effects and implications of the public data ambience are global. The ambient information environment today is information-rich: a stark contrast to the one in which I will now term 'historical ambient music' was first presented. R. Murray Schafer, in his introduction to The Tuning of the World notes that "the ear demands that insouciant and distracting sounds would be stopped in order that it may concentrate on those which truly matter". ${ }^{9}$ Today, what was insouciant and distracting in 1977 when The

7 Brian Eno, Ambient 1: Music for Airports, (LP) (London: Editions E.G. - AMB001, 1978).

8 Brian Eno, Ambient 4: On Land (LP) (London: Editions E.G. - EGED 20, 2335 228, 1982).

9 R. Murray Schafer, The Tuning of the World, (New York: Alfred A. Knopf, 1977), 12. 
Tuning of the World was first published may in fact be part of the richness of the contemporary sound environment.

\section{The pervasive ambience}

Jean-Paul Thibaud introduces the idea of pervasive quality, tracing the notion back to Dewey's philosophy on situation. Thibaud uses the idea of pervasive quality as a perceptual short-hand for describing ambience through the least amount of information possible. Pervasive quality then is very much like a label or a tag by which the components of an ambient environment might be bundled together in order to humanly recognise and assess them. Thibaud writes:

[...] Dewey introduced the notion of 'pervasive quality' (Dewey 1931). This notion is particularly important and is perhaps best grasped as another way of referring to ambiance. The three components used to define pervasive quality certainly all concern the notion of ambiance itself. Quality as Unity First, for a situation to exist, all the components of a context must be integrated within a single quality $[\ldots]^{10}$

The work of Neuroscientist Eric Miller provides insight into why a generic model of ambience (and hence, listening strategies built upon this idea) has proven so sustainable:

[...] we have evolved the ability to detect the commonalities among experiences and store them as abstract concepts, general principles and rules. This is an efficient way to deal with a complex world and allows the navigation of many different situations with a minimal amount of storage. It also allows us to deal with novelty.

10 Jean-Paul Thibaud, "The Sensory Fabric of Urban Ambiances," The Senses and Society, 6(2), (2011): 206, DOI: $10.2752 / 174589311 X 12961584845846$ 
By extracting the essential elements from our experiences, we can generalize to future situations that share some elements but may, on the surface, appear very different. ${ }^{11}$

Miller's description of this process aligns well with Thibaud's analysis of pervasive qualities. We reduce the world into a set of generalisable situations in order to cope better with the challenges of the future. Ambience then, when viewed as a non-changing, non-personal quantity might be packaged and labelled as a single entity. ${ }^{12}$ However, I propose that these simplification processes should be confined to the memory and recall models within perception as Miller intends, and not to information-gathering processes. Decoding sound (and music) in our environment concerns both recall and situational analysis in real-time.

\section{Ambient overlay and augmentation}

A change to reception processes occurs when music acts as a perceptual overlay to an environment. When music overlays an ambient sound environment, traditional musical reception processes struggle to describe the results. In addition, scholarly work in musical analysis, such as that documented by Jonathan Dunsby and Arnold Whittall ${ }^{13}$ carries an assumption that the music is the sole focus of our attention in such circumstances, and not an overlay layer to other information with which it might also have a complex set of relationships. Musical analytical tools, such as Schenkerian analysis or set

11 Earl K. Miller, David J. Freedman, and Jonathan D. Wallis, "The prefrontal cortex: Categories, concepts and cognition," Philosophical Transactions of the Royal Society B: Biological Sciences 357(1424), (August 2002): 1123, https://doi.org/10.1098/rstb.2002.1099

12 See Andrew Bourbon, and Simon Zagorski-Thomas, "Sonic Cartoons and Semantic Audio Process: Using Invariant Properties to create Schematic Representations of Acoustic Phenomena," Proceedings of the $2^{\text {nd }}$ AES Workshop on Intelligent Music Production, London, 13 September 2016, 2, who demonstrate this perceptual mechanism happens frequently in Audio in the form of Sonic Cartoons.

13 Jonathan Dunsby, and Arnold Whittall, Music analysis in theory and practice (London: Faber Music, 1988). 
theory, can only function where music, rather than environment plus music, is the auditory input. Whilst nobody would expect Schenkerian analysis to include an understanding of the current real-time peripheral audio background in addition to the structural background of the music, traditional Western analytical methodology needs to change to encompass situations where the ambient environment is considered to carry detailed and relevant perceptual information within it.

The idea of overlay is derived from early augmented reality thinking, ${ }^{14}$ however, overlays themselves are only a component part of an 'augmented' environment. Overlaying information onto an environment will only become an augmentation when that overlay makes connections between the environment and our perception of it. Simply introducing different or new information (such as music) into an existing environment (our surroundings) does not automatically generate specifically augmentative connections. ${ }^{15}$ The purpose of overlaying information, I propose, is one by which affordances ${ }^{16}$ are generated. Each new information layer that is added to a situation contributes a new means of exploring and interacting with an environment. Music that is designed to become part of our ambient environment operates as an information overlay in this sense. The nature of the resulting affordances generated may be either limited in scope, through a purposeful lack of semiotic connection (such as in the case of 'background music'), or designed to be interactive and enabling, such as in an installation where embodied behaviours are provoked. This latter idea is demonstrated by Tia DeNora ${ }^{17}$ in her description of functionality in music accompanying exercise regimes.

14 See Thad Starner, Steve Mann, Bradley Rhodes, Jeffrey Levine, Jennifer Healey, Dana Kirsch, Rosalind W. Picard, and Alex Pentland, "Augmented reality through wearable computing," Presence: Teleoperators $\&$ Virtual Environments 6(4), (1997): 386-398.

15 It will of course generate a multiplicity of other semiotic connections - see Jean-Jacques Nattiez, Music and discourse: Toward a semiology of music (Princeton, NJ.: Princeton University Press, 1990) for an introduction.

16 See James J. Gibson, The Senses Considered as Perceptual Systems (Boston: Houghton Mifflin, 1996).

17 Tia DeNora, Music in Everyday Life (Cambridge: Cambridge University Press, 2000). 
DeNora suggests that music (overlay) enables us to view the environment (ambient information) in ways which afford bodily capacities. In this way, she views music as a "prosthetic technology", permitting the perceiver or participant of an everyday physical event to find new ways of interacting with that situation. The differences between what constitutes overlay (the act of introducing a new layer of information) and what is augmentation (in this context, the ability to perceive an environment in a new way as a result of the overlay) are precisely those which separate today's ambient information environment from ideas presented in ambient music from the 1970s. Augmentation is a concept which requires personal engagement, and new forms of interactivity. It is also those qualities which delineate contemporary approaches to music and sound from the 'ambience', from those which became crystallised and embedded into historical positions on ambient music. Eno's Ambient 4: On Land (1982) could be overlaid anywhere. It does not matter where that overlay takes place, or even if it does not take place. However, in contemporary music which accesses the ambient information environment to create augmentation, where an overlay takes place is of vital importance to the artwork. In making an overlay, or even an augmentation, it is important to consider what has been suppressed in doing so. Paul Roquet suggests that Eno's On Land is a form of landscape painting, quoting Eno:

The idea of making music that in some way related to a sense of place-landscape, environment-had occurred to me many times over the years preceding "On Land". [...] My conscious exploration of this way of thinking about music probably began with "Another Green World" (1975). On that record I became aware of setting each place within its own particular landscape and allowing the mood of that landscape to determine the kinds of activity that could occur. ${ }^{18}$

18 Paul Roquet, "Ambient Landscapes from Brian Eno to Tetsu Inoue," Journal of Popular Music Studies 21(4), (December, 2009): 367. 
Distilling landscape to generic mood creates the sense of overlay because low-level detail is smoothed out, if not totally suppressed. Malcolm McCullough ${ }^{19}$ points out that digitally augmenting everyday life has significant consequences, including a removal of important low-level contextual information. In analysing how digital media creates a sense of "ambient commons" McCullough shows how the information flow from the underlying environment has become suppressed. Beneath the augmentations, he argues, is a "high resolution" environment. In doing so, McCullough uses language similar to that of R. Murray Schafer in describing the situation. However, McCullough's use of "high resolution" is not burdened with having also to account for distinctions in perceived quality between environments ('hi-fidelity'- Schafer).

\section{Part 1: Ambient as environment}

The methodology and concepts set out by Schafer within The Tuning of the World have been influential in defining the fields of acoustic ecology and soundscape composition. The original definitions and scholarly tools generated by this work are still in widespread use today. This is where the problem lies: the ambient environment today is not at all like the one investigated by Schafer in 1977, and the reasons for understanding the ambient environment have widened within that time to reflect changing cultural needs and situations. Some adjustments are proposed here, by way of starting points, in an attempt to supplement this work.

\section{Rethinking the soundscape}

At this point, I will aim to show that encoded within Schafer's methods for describing soundscapes is an assumption that the ambient information environment is a passive presence, constructed using values which draw

19 Malcolm McCullough, Ambient commons: Attention in the age of embodied information (Cambridge MA.: The MIT Press, 2013), 102-105. 
on the pervasive characteristic views of Thibaud, Dewey (in Thibaud) and Miller presented earlier. ${ }^{20}$ Instead, an alignment between environment and soundscape is advocated which draws on contemporary psychology and information science. It is proposed that the ambient environment is not a singular passive presence, rather a data-rich source of multiple, diverse information streams.

\section{Beyond Lo-Fi and Hi-Fi soundscapes}

The first adjustment to Schafer's thinking to consider is that ambient environments, regardless of where they sit in our perceptual focus, are complex and information-rich. In order to make this adjustment, we need to deconstruct a hierarchical relationship key to Soundscape theory: the idea itself of lo-fi and hi-fi soundscapes. ${ }^{21}$ Schafer quantified the 'fi-ness' of soundscapes by aligning them to a metaphor from electronics and communications: the signal-to-noise ratio. Signal-to-noise ratio is predicated upon the successful transmission of a 'message' free from unwanted polluting 'noise' content. Hifi soundscapes were acoustic environments with a high signal-to-noise ratio, and lo-fi those where the 'message' is barely distinguishable over the noise. ${ }^{22}$ In both cases, noise is positioned as the opposite of information. While convenient, this dualism has knock-on effects of creating polarised divisions between foreground and background, active and passive listening, focus and far-field, intention and non-intention, urban and rural, private and public. What if that is not how we listen? Could it be that the lo-fi background has greater information content than the foreground? What if the mechanical drones of urbanity carry essential information: city dwellers can tell from sound what time of day it is, what the weather is doing, and when would be a good time to commute - all from the 'din' of the city. Sound within the

20 In doing so, it is acknowledged that some ambient environments may still function is this way.

21 R. Murray Schafer, The Tuning of the World, 43-71.

22 Ibid., 71-87. 
urban landscape today is as much foreground and private as it is background and public. Likewise, the $b i-f i$ soundscape of rural communities in remote locations can still signify the absence of employment today, rather than pastoral bliss.

According to Schafer's theory, a soundscape is labelled lo-fi or hi-fi through the analysis of a low number of dominant features present within it. Yet, in many acoustic environments the absence of certain types of sound are as perceptually important as their presence. If this is the case, then constructing binary relationships between lo-fi and hi-fi soundscapes becomes difficult. Instead, it is more productive to look at the types of information presented by an environment and our human relationships to them.

Soundscapes: who are the listeners?

Barry Truax and Gary W. Barrett point out that a purpose of Schafer's soundscape programme was to try and combat everyday modes of perception that are frequently applied to soundscapes, "to counter the types of soundscapes that produced a non-listening habituated response to the acoustic environment". ${ }^{23}$ [author's italics]

The idea of a 'listening' response to soundscape has created controversy as authors have sought to question why a composerly, structured reading of the soundscape is any more (or less?) important than a 'non-listening' one. Illustrating this tension, Elizabeth Weybright ${ }^{24}$ assesses the sonic descriptions contained within the poetry of Dorothy Wordsworth from circa 1800, and makes comparisons to the ways in which soundscapes were subsequently documented. Weybright concludes:

23 Barry Truax, and Gary W. Barrett, "Soundscape in a context of acoustic and landscape ecology," Landscape Ecology 26(9), (2011): 1203.

24 Elizabeth Weybright, "The Everyday Soundscape: Sound and Mixed Aesthetic Modes in Dorothy Wordsworth's Journals," European Romantic Review 28(3), (2017): 325-332. 
This elevation of mundane non-musical sounds - noise - to the status of soundmarks offers a radical early ecological version of contemporary sound studies' attention to unorganized ambient noises as potentially meaningful long before Western philosophy will begin to concern itself with the possibility that non-musical (i.e., not composed according to a tonal system, not necessarily human) sound might have aesthetic value. ${ }^{25}$

Although human musicality can reside far beyond activity contained within a tonal system, Weybright's central point that the ambient environment carries detailed information content and does so in a way that does not need it to be conceptually adjusted in status to permit it to be of value, is important. Furthermore, the conceptual reduction of sonic environments to musical parameters can create value differences between listeners. Kim Foale writes:

Schafer judges soundscapes based on the perspective of the connoisseur, judging soundscapes the most pleasurable that have little or no people in, where sound and land respond in tangible, 'beautiful' ways. Truax and Barrett (2011) summarise the concepts in this approach as acoustic composition, temporal dynamics, spatial variability, and acoustic interactions, typical priorities for composers (like Truax), less so perhaps for laypeople. ${ }^{26}$

Ambient sound environments typically communicate information that we need to culturally or physically take notice of. They are not themselves 'temporal dynamics', or functions of 'spatial variability'. These are observed characteristics that reference particular musical aesthetics where elements of flow, pacing and space are organising factors. Unfortunately, this type of

25 Weybright, The Everyday Soundscape, 329.

26 Kim Foale, A Listener Centered Approach to Soundscape Analysis (Unpublished PhD thesis: Salford University, 2014), 19. 
analysis can itself function - through the act of structural metaphor - as a form of reduced listening ${ }^{27}$ behaviour. I have previously argued that reduced listening was a convenient way of legitimising the inclusion of real-world sound material for 1950 s concert audiences ${ }^{28}$ as it packages sound events which may at the time have been considered to be 'non-musical' into structures which can be decoded musically. Reduced listening is a powerful conceit, helping to bind listener to composer. This is not itself a negative proposition, and such structures play a large part in how music communicates to particular audiences. It is also worth noting that Pierre Schaeffer himself did not stray away from the subjective and cultural elements of sound in his assessment of their compositional qualities. Given that we can listen to ambient sound musically, it does not mean that we need to. As Foale points out, this is not in any way a special process, or that not listening 'musically' is any better or worse, thrilling or dull, than if we choose otherwise. Ironically, if we listen 'musically' - even in the broadest sense of the word - could we be limiting our exposure to the underlying ambient information and the relationships it contains by listening through a frame of past aesthetics, criteria and judgements?

\section{Listening modes and the ambient environment}

Barry Truax separates definitions of listening modes into Listening in Search, Listening in Readiness, and Background Listening. ${ }^{29}$ Truax acknowledges that all forms of listening are not mutually exclusive. However, modes of listening can be understood as being implicitly linked to categories of environment, in a manner consistent with R. Murray Schafer's approach to soundscape. For

27 For an explanation of reduced listening see Pierre Schaeffer, Traité des objets musicaux (Paris: Le Seuil, 2016), 114-117.

28 Ambrose Field, 2016, "Simulation and reality: The new sonic objects," Music, Electronic Media and Culture, ed. Simon Emmerson (Aldershot: Routledge, 2016), 46-65.

29 Barry Truax, Acoustic Communication (2 ${ }^{\text {nd }}$ Edition) (Westport, CT.: Greenwood Publishing Group, 2001), 19-24. 
example, by extending the scope of Truax's argument it is illogical to expect listening in readiness to occur when we are already listening in search, and for background listening to provide meaningful data to our perception, as in this model, background listening is the 'default' process from which our perception is shifted into other states in order to recover detail.

Background listening is something considered to happen when there is little to no resolvable information content. Carolyn Jennings ${ }^{30}$ points out that both top-down and bottom-up processes are responsible for conscious perception, and that these are steered by personal interest. As such, any act of 'generalizing' the ambience will be individual, specific, and will change over time. These parameters are not considered in theories relating to static modes of listening, and the sonic complexity of the ambient environment is still available to the real-time elements of our reception process. Both topdown, and bottom-up perceptual mechanisms are at work in determining the relationship between ambience as background and ambience as information. Notably, the idea of environment as information becomes particularly relevant in Truax's analysis when Listening in Search or Readiness is activated (and consequently consuming foreground attention). Only at that point is the specific information which caused the change presumed to be present. Meanwhile, for Truax's background listening, the environment appears to be a firmly situated one, located within a spatial domain around ourselves. If an ambient environment is non-situated and self-constructed, a three-tier set of listening processes now seems unable to represent the relationships we can either observe or design within creative work. This notion is explored in Part Two of this chapter. In expanding these definitions, the surrounding ambient environment can become more personal and responsive, a challenge explored by artists placing ideas of embodied cognition at the heart of their practice.

30 Carolyn D. Jennings, "Attention and perceptual organization," Philosophical Studies 172(5), (2015): 1265-1278. 
Noise, ambience and detail

Peter A. Coates demonstrates that the idea of 'noise' has become intertwined with distinctions between sounds made by humans, technology, and the natural environment. It is not the scope of this study to define or analyse noise ${ }^{31}$, rather to draw attention to the persistence of a value set which rejects non-human, environmental sound as being 'other' in perceptual terms. Coates points out that for the American National Parks service, 'quiet' is defined as the absence of human agency,

[...] the park service defines natural quiet as the absence of manmade sounds. This conflation of man-made and technological sounds is common practice among today's crusaders for natural quiet. The problem, of course, is that this reinforces the uncompromising divide between humans and the rest of nature. ${ }^{32}$

Rejecting non-human agency in the ambience has a consequence of creating hierarchical distinctions between sounds, and those hierarchies are not present in how human auditory perception analyses the information content of environments. Peter Lennox, John Vaughan and Tony Myatt have researched the nature and importance of small-scale sonic detail within surround sound audio environments, concluding that audio systems tend to focus on the perceptual foreground, leaving a perceptual lacuna in the form of a lack of low-level ambient detailing:

From the neurosciences there is strong evidence of innumerable parallel connections between many areas of the cortex at all levels, and from higher levels to more peripheral ones. This provides for

31 See Paul Hegarty, Noise music: A history (New York: Bloomsbury Academic, 2007) for an historical context.

32 Peter A. Coates, "The Strange Stillness of the Past: Toward an Environmental History of Sound and Noise," Environmental History 10(4), (2005): 653. 
multiple 'what' and 'where' processing streams, at least in the visual system, and it is reasonable to suppose that analogous processes are available in the auditory domain. ${ }^{33}$

A simple perceptual structure for assessing the binary division of lo-fi versus hi-fi soundscapes and then making value decisions between them is, on this basis, neurologically unlikely. ${ }^{34}$ It is time to evolve new descriptions for soundscapes which do not force sound to be measured against cultural and geographic norms from the past.

Silence and mediation in ambient environments

His most infamous work, 4'33" (the so-called silent piece), framed an unmediated world of sound; by inviting listeners to attend to an acoustic experience not structured by a performer, Cage effectively asked listeners to themselves become composers. ${ }^{35}$

Often, the ambient environment is understood as being un-mediated, particularly as communication can be accomplished through direct signs and tacit understanding. However, tacit communication does not mean per se that there is no agency or embodiment taking place. Sound is generally produced by agency, even if it is the wind or emitted as a by-product of activity elsewhere within the electromagnetic spectrum. The agencies behind the ambient sound environment are complex and multiple, often transmitted

33 Peter Lennox,John Vaughan and Tony Myatt, “3D audio as an information-environment: Manipulating perceptual significance for differentiation and pre-selection," Proceedings of the $7^{\text {th }}$ International Conference on Audio Display (ICAD2001), Espoo, Finland, July 29 - August 1, 2001, eds. J. Huupakka, N. Zacharov, and T. Takala, International Community for Audio Dispay, 2001: 7.

34 Bregman's definitions of Auditory Streaming do not support such a polarisation in the categorisation of complex auditory objects. See Albert S. Bregman, Auditory scene analysis: The perceptual organization of sound. (Cambridge, MA.: The MIT press, 1994).

35 Mitchell Akiyama, "Transparent Listening: Soundscape Composition's Objects of Study," RACAR: revue d'art canadienne/Canadian Art Review, (2010): 59. 
through tacit mediation rather than overt intervention. Describing the ambient environment as un-mediated is problematic, as it contains the blueprints of mediation: causality, culture and personality.

In Recording Carceral Landscapes, Trevor Paglen ${ }^{36}$ describes how in his work documenting some of California's toughest penitentiaries the only common thread is one of silence. At this point, we need to question Cage's assumption of musical value (in the widest sense) in the ambience, no matter what that might be, as the 'silence' described by Paglen surely would not have been truly silent. It is the suppression of other sound in the ambience, the humans, which give Paglen's descriptions power and purpose. It would be straightforward to align this situation to that of negative space through the Chinese poetic idea of 意境 (Yi Jing) ${ }^{37}$ or the Japanese concept of 間 (ma), inviting us to imagine that what is not present is as essentially as valuable as what is. However, this is not ma: this is a real space, filled with negative content where imagination is not necessary to understand the direct and tacit nature of the communication between environment and human, and this is not Yi Jing: there no sense of poetic connection or balance between nonobserved and observed elements of the world. Paglen writes:

After reviewing tapes from the SHU at Pelican Bay, it was the silence that struck me most: the banal uneventfulness at the core of one of the most brutal prisons in the California system - a system that is the paradigm of the "Prison Industrial Complex". The recordings revealed no sinister secrets, no hidden truths, no smoking guns. The silence of the SHU is the silence of both "business as usual" and total domination. ${ }^{38}$

36 Trevor Paglen, “Recording Carceral Landscapes," Leonardo Music Journal 16, (December 2006): 5657, https://doi.org/10.1162/lmj.2006.16.56

37 意境 literally translated means 'poetic world' or 'artistic conception', used in a manner to express the notion of balance between elements within the design.

38 Paglen, Recording Carceral Landscapes, 57. 
Notions of temporal dynamics or spatial variability are not required here to decode this situation. The ambience is mediated through the act of incarceration and the resulting sound world can be clearly connected with a serious societal situation.

\section{Part 2: Ambient as personal identity}

In order to understand how music interacts with our present information environment, I will argue that two ideas, the spatial self ${ }^{39}$ and subject centred organisation $^{40}$, are particularly important in determining what ambience might be. When coupled with an understanding of embodied cognition ${ }^{41}$ it is possible to describe ambience from the perspective of the perceiver.

Schwartz and Halegoua's notion of the spatial self suggests that a contemporary sense of external identity is constructed not just through online personal media but in how we choose to interact with and curate the digital information which attaches itself to our geolocation. Importantly, this idea is not specifically concerned with presence within a location ${ }^{42}$ but more with the impact that that location has on how we describe and present ourselves. The authors acknowledge that this presence is curated and managed, and that we are actively involved in refining it as time passes. Such techniques are not limited to digital media. In effect, what was once a sense of stasis associated with physical place has become morphed into a dynamic, active and personallybranded phenomenon. The idea that public physical space can be subject to personalisation, comment, viewpoint and subjective association is not new. However, this concept of the spatial self, made malleable through digital media, can shed light on the types of relationship exhibited between ambient music

39 See Raz Schwartz, and Germaine R. Halegoua, "The spatial self: Location-based identity performance on social media," New Media E Society 17(10), (2015): 1643-1660.

40 Jennings, Attention and perceptual organization, 1265-1278.

41 See Marc Leman, Embodied music cognition and mediation technology (Cambridge, MA.: The MIT Press, 2007)

42 Almost a contradiction to the soundwalks of acoustic ecology. 
and the environment. Martin Dust in 2010's FACT magazine observed a disconnection between a personal view of space and Eno's vision for Music for Airports, remarking that: "I understood that [Eno] were pitching it at a utopian vision, but for us it just seemed so out of place, like something from a sci-fi film" ${ }^{43}$ Victor Szabo ${ }^{44}$ indicates that part of such a disconnect might lie in the absence of sounds from the physical environment, citing The Black Dog's Music for Real Airports ${ }^{45}$ by way of an alternative. Could it be that rather than lacking in the physical sounds of airports per se, that the 'out of placeness' reported by Martin Dust himself is due to the fact that we sculpt our experience of airports personally: no amount of adding the sounds of jet planes, baggage checks or security officers will necessarily add to our received sense of reality. The spatial self, as a dynamic changing form, is responsible for this and acknowledges that the airport yesterday will not necessarily be the same for us as it is today. The sounds fixed in time in Music for Real Airports come from a past reality. Although this is one which travellers might identify with, it is not one which is necessarily part of a spatial self. This incompatibility results in a sense of aural dislocation. Fixing environments in time, without active participation in imagining possible past and future spatial selves, will not automatically help our connection to those environments. Situating environments in a past time also consigns them to the category of ambient overlay rather than augmentation, regardless of whether the music is performed within that environment or appreciated at arm's length in a comfy armchair.

Against pervasive ambience: context switching and detail recovery processes

Human perception of ambient information can be unpredictable and

43 Martin Dust, "The Black Dog: Music for Real Airports," in FACT Magazine: Music Newws, New Music. Accessed: July 20, 2018, https://www.factmag.com/2010/05/12/the-black-dog-strange-cargo/.

44 Victor Szabo, Ambient Music as Popular Genre: Historiography, Interpretation, Critique. (Unpublished $\mathrm{PhD}$ thesis, University of Virginia, 2015).

45 The Black Dog, Music For Real Airports, (UK: Soma Quality Recordings, Soma - TBD003, 2010). 
immediate shifts of attention can occur due to a complex interaction between personal factors and the physical environment. Therefore, it is unlikely that there is any one sense of what a background ambience might be. Perceptual mechanisms for assessing the outside world rely on context-switching to help decode environmental events from a large number of simultaneous sources, as demonstrated by Lauren A. Newell. Newell highlights the concept of context switching as part of an apparatus to deal with ambient information events, stating that "we are born to be interrupt driven". ${ }^{46}$

Newell shows the cost of context switching in mental terms on task performance, suggesting that it is information from our ambient environment which is often responsible for a degree of perceptual steering which occurs within this. Distraction, according to Newell is not an information-poor state; being distracted is the result of intensive information processing. Such an idea throws into sharp relief the calm presentation of ambience in 1970s early electronica. Through this lens, this music appears to be the opposite of the ambient environment which surrounds us today. Opposition to the 'real' ambience of today is the contemporary charm of this repertoire. Acknowledging the information richness of today's ambient environments points to a new type of thinking in contemporary approaches to musical creativity which deal with reality at their core. Michael Gallagher ${ }^{47}$ has reviewed the field recording practice of sound artists such as John Levack Drever, and this research demonstrates that today's field recording-based creative practices can be associated more with contemporary notions of ambience as detail, than past assumptions of ambience as generic perceptual background. Gallagher extends this notion of specificity into the idea of Sonic Geography, enabling places to be experienced in new ways through audiomediated personal reflection.

46 Lauren A. Newell, "Redefining Attention (and Revamping the Legal Profession?) for the Digital Generation," Nevada Law Journal, Vol.15(2): 763.

47 Michael Gallagher, "Sounding ruins: Reflections on the production of an 'audio drift'," cultural geographies 22(3), (2015): 467-485, http://doi.org/10.1177/14744474014542745 


\section{Subject-centred organisation}

Importantly, how perception shifts from analysing complex environmental information to a sense of singular focus is understood to be a highly personal and subjective process. Thibaud ${ }^{48}$ suggests that today, the notion of the ambient environment is itself a subjective one. Supporting this assumption is the idea of subject-centred organisation. ${ }^{49}$ Subject-centred organisation concerns building environmental meaning around individual value-sets. This idea is not without musical precedent.

The work of Maryanne Amacher, for example, is music which is probably as simultaneously a-contextual and individual as can be. In Sound Character ${ }^{50}$ textures are formed through sum and difference tones which are only constructed in the ear itself. It is almost as if audience members are held responsible for bringing the discrete streams of the composition together. In doing so, Amacher demonstrates that details within the ambient environment can carry significant musical information.

Environmental meaning that can be understood through subject-centred organisation theory lies at the heart of Maja S. K. Ratkje's Desibel [sic]. ${ }^{51}$ Powerful electro-acoustic horns are located within a fjord, in which a dispute with a mining firm has taken place. Extremely loud sounds are emitted into the landscape through these devices, encouraging listeners to think carefully about their personal role within the landscape. The difference in scale between the sound of the horns (an unusual and unmistakable intrusion within an environment) and the environmental background sound (the ambience - a 'normal everyday sound') is huge. Ratkje writes:

48 Thibaud, The Sensory Fabric of Urban Ambiances, 213.

49 Jennings, Attention and perceptual organization, 1266.

50 See Gascia Ouzounian, "Embodied sound: Aural architectures and the body," Contemporary Music Review 25(1-2), (2006): 69-79.

51 Maja S. K. Ratkje, Desibel (2009), accessed: June 15, 2018, https://vimeo.com/15852821 
Desibel was also made as a protest against the plans of a major mining project in Vevring, a quiet village situated in the district of Sunnfjord. The concession is owned by Nordic Mining. The mining will cause 200,000,000 cubic meters of contaminated waste to be dumped every year into a valuable national salmon fjord. Only four percent of the mountain will be used in various commercial interests. The mining will go on for 24 hours a day, 7 days a week for 30 years. Desibel is a protest against ruthless exploitation of natural resources and against short time profit thinking [...] The sound of seagulls is also present an absurd, over-sized response to the mining company's promise that the mining work will only be as loud as the seagulls. ${ }^{52}$

If, as Dicey Jennings suggests, human processes for switching focus and filtering complexity, are driven in this way through a mechanism which thrives on detail, we can start to unpack the compositional implications for space and place in new ways. The work of Jana Winderen ${ }^{53}$ points to values which are important in forming a contemporary understanding of what ambient, and ambient music, might be. Winderen has recorded and produced detailed recordings of environmental scenes. Calling them 'soundscapes' is perhaps a mis-representation, as the term embodies a certain sense of amalgamating detail into a single container form representative of the environment (the 'scape'-ness within soundscape). Winderen's work goes far beyond the generic, providing detail in that environmental representation combining insight into geological and living processes in such a way that is well suited to attentive listening and personal discovery. This is particularly the case in Energy Field ${ }^{54}$ where small-scale sound-events are presented among spectrally dense, rumbling environmental drones. The construction

52 Maja S. K. Ratkje, Notes for Desibel, accessed July 21, 2018, http://ratkje.no/2009/10/desibel/

53 As discussed in Cathy Lane, and Angus Carlyle, In the field: The art of field recording. (Devon: Uniformbooks, 2013), 147-159.

54 Jana Winderen, Energy Field, (UK: Touch Records - TO:73, 2010). 
of this work evades specific geographical location from sound alone, but this is not, however, coupled with any reduction in information about the environments it portrays. Anette Vandsø argues that this context is externally generated:

Seen from the point of reception, the very simple answer to how these context-based compositions establish their aboutness is that the context is told (Milutis 2008). Whether we are listening to the sounds of underwater life in Jana Winderen's tape release or the traffic network in the Ruhr district as in Kubisch's installation the context is told by curational notes and titles that are placed in relation to the artwork..$^{55}$

Vandsø is commenting on Winderen's earlier release The Noisiest Guys on the Planet ${ }^{56}$ with which Energy Field shares some constructional methodology: drones feature heavily, against which other materials are exposed each with their own sense of carefully constructed space. If 'aboutness' and Vandsø's ideas of 'context-based composition' are taken to be indicators of geographical location, it may well be hard to determine these qualities from the recording alone. However, following a revised definition of 'ambient', where subtle detail provides high levels of information content, the 'context' presented in this recording is incredibly vivid. I would argue that no 'contextualising narrative' or 'paratext' can substitute for it. It is this difference that separates Winderen's work from a more traditional approach to acoustic ecology. Winderen hints at ambient detail as an uncharted resource:

Also the fact that the sensitivity to these audible landscapes, invisible but audible, have developed for millions of years. Some

55 Anette Vandsø, "Four Key Concepts for Studying Context-based Compositions," Organised Sound 23(01), (Cambridge: Cambridge University Press, 2018): 5.

56 Jana Winderen, The Noisiest Guys on the Planet (UK: Ash International - ASH 8.1, 2009). 
species have adapted to their environment without light for so long. They understand vibrations and sounds in a different way. ${ }^{57}$

If, as Daniel Levitin ${ }^{58}$ suggests, detail is spatially wedded to the original environment through neural mechanisms for retrieving information, then it is going to be difficult to think that a recorded environment - however vivid - can ever truly 'transport' listeners. ${ }^{59}$ In this way, music from the ambience is not necessarily about re-mapping one listening environment onto another. Perceptual cues to location which are locked into real-world environments may have no causal plausibility within the environment in which we are listening. I will propose that, contrary to traditional theory, this does not always create schizophonia ${ }^{60}$ as our auditory perception can make clear distinctions between recording and reality regardless of any implied semiotics carried by the medium. Whilst two or more distinct spaces can be presented at the same time, through technology or in reality, the element of disunity which lies at the root of the notion of schizophonia is, in fact, not problematic and part of normal perception of complex environments. Megan A. Reich observes a similar situation in Winderen's music:

By considering all sounds of the soundscape as a source of both data and music (sounds inherently worthy of aesthetic appreciation, whether or not they were "intended" by a composer), the question 57 Tobias Fischer, Interview with Jana Winderen, accessed: July 21, 2018,
http://www.tokafi.com/15questions/interview-jana-winderen/

58 Daniel Levitin, The organized mind: Thinking straight in the age of information overload (London: Penguin, 2014), 83.

59 The argument here is not about 'transport' in a physical sense - but about providing a perceptually convincing sonic representation. The idea of transport - in any form - depends on imagination to function.

60 R. Murray Schafer, The Tuning of the World, 90. 
of noise for composers like Winderen is no longer even an issue. ${ }^{61}$

In none of these examples is the environment a generic, single entity. Both Winderen and Ratkje frame the listener (rather than the piece) in new ways: we are not asked to transport ourselves to another location (as in some acousmatic and soundscape music) but instead re-consider our personal involvement with a situation. Whilst listening to Ratkje's Desibel, listeners can consider their role in a political situation - even if they are not part of the specific community affected by the piece. The human relationship with the environment is also questioned through Winderen's piece, via a consideration that the most abundant species on the plant is not humankind, but shrimp.

\section{Part 3: De-situating ambience}

Having acknowledged the role of the spatial self in constructing the feeling of situatedness, it is worth noting that not all real-world ambient environments today are permanently situated in any location in particular. Amparo Lasen ${ }^{62}$ introduces the idea of portable urban space, a type of space generated through the interaction of mobile technology in urban environments. Lasen is not just speaking of listening to music in a physical location: his argument concerns how presenting our choices, as defined by personal spatial identities, influences the information present within our ambient environment. In a way, this idea is the reverse of the spatial self: here, personal information is generated and flows back to the environment. Lasen says this is done through the means by which music is shared in public, through headphone spill or through group listening. Synthesising the views of Lasen and Schwartz, the definition of ambient urban environments is now one that is no longer situated. Urbanity in sonic terms

61 Megan A. Reich, Soundscape Composition as Environmental Activism and Awareness: An Ecomusicological Approach, (University of Puget Sound: Sound Ideas 2016), 21, accessed April 8, 2019, https://soundideas.pugetsound.edu/cgi/viewcontent.cgi?article=1472\&context=summer_research

62 Amparo Lasen, "Disruptive ambient music: Mobile phone music listening as portable urbanism," European Journal of Cultural Studies 21(1), (2018): 96-110, https://doi.org/10.1177/1367549417705607 
is personal, cultural, evolving and dynamic. The notion of portability of space must ultimately have a boundary (spaces cannot simply be made portable to anywhere else by default, and personal information may not be relevant in spaces other than those for which it was originally intended). That boundary is cultural as much as it is physical. When designing music for portable urbanism (the way in which music forms a set of personal and dynamic associations to specific places, times, and locations) we still may need a means to situate that experience in more general terms. Christopher J. Cox and Mirko Guaralda ${ }^{63}$ underline this malleability of space, demonstrating how activities ranging from urban hacking to busking can be seen to be the product of an environmentally relevant form of spatial ownership. Jean-Yves Bosseur similarly writes about the musical occupation of Urban ambience. He suggests that music is not just the consequence of space, but that architectural space within our cities can be defined by music. In doing so, Bosseur identifies the effect of musical pollution on our ambient noise environment and assesses the legacy of the Muzak corporation. ${ }^{64}$ Today, what is perceived as pollution can come from foreground distractions and not ambience.

We have, at this point, arrived at a sense that there is potential for complex personal interaction within a domain often thought to be 'peripheral'. New 'ambient' musics are responding to the challenges of presenting greater detail and more defined opportunities for personal interaction. Thus far we have established that the ambient information environment is feature-rich, personally-directed, portable, and not necessarily situated. This view now seems at odds with well-known definitions of listening strategy and process. In addition, it calls into question the relevance of foreground, feature-based descriptors (such as soundmarks) discussed earlier, due to the absence of structures to capture adequately the human involvement with those features.

63 Christopher J. Cox, and Mirko Guaralda, "Public Space for Street-Scape Theatrics. Guerrilla Spatial Tactics and Methods of Urban Hacking in Brisbane, Australia," The Journal of Public Space 1(1), (2016): 113, https://doi.org/10.5204/jps.v1i1.14

64 Jean-Yves Bosseur, Musique et environnement (Paris: Éditions Minerve, 2016), 101-127. 
Towards an embodied perception of ambient space

Embodiment ${ }^{65}$ plays an important role in understanding the ambient environment, accounting for human ways in which multiple concurrent sources of information can be assessed. Music can engage on a number of levels with embodiment concepts. For example, listeners to 'traditional' concerts of Western art music may not engage with any form of physical reality other than where music is present as sound. ${ }^{66}$ This mode of concert presentation has strong similarities with the presentation of much historical ambient music, in that it is passive and detached from embodiment. The view of ambience as perceptual background also embeds within it an assumption that ambience itself is an arms-length quantity. Contrast this approach with that of the proactive exploration of ambient environments, a central feature of the work of Christina Kubisch. Much of her music involves physical agency on the part of the perceiver, and also on the part of the creator (which may, in a vast number of cases be mechanical or non-human). Participants on an Electrical Walk (electromagnetic sound walk) ${ }^{67}$ are given equipment which 'auralises' information (through electromagnetic transformations) within our ambient environment. The results are astonishing: the environment's hidden rhythms are revealed and a polyphony of unseen and unheard interactions emerges. The action of selection rests with the perceiver and as new physical locations are uncovered, a new sense of connection to those locations emerges through personal choice. Importantly, such a practice is different from the 'sound walking' of the 1980s. There is no intention to define space directly through these sounds: they do not exist as sound, they are not 'soundmarks' as R. Murray Schafer would put it. Instead, an interpretative process, involving

65 See Raymond W. Gibbs Jr., Embodiment and cognitive science (Cambridge: Cambridge University Press, 2005).

66 Leaving aside for a moment that any music can be used to accompany virtually any known physical action if so required.

67 Cathy Lane, and Angus Carlyle, In the field: The art of field recording, 67. 
both technology and personal choice is at work, and as such it brings the 'spatial self' closer to the everyday.

\section{Conclusion}

The embodied, detailed and individual exploration of ambient sound has more in common with contemporary definitions of a complex ambient information environment than musics which specifically carry the ambient genre label. Ambient music as a genre can be seen as an information overlay, not an interaction with an ambient environment. As such, there is space in the ambience for ambient music, but how ambient music is socially connected to the ambient environment has changed in the 40 years since its inception. This chapter has proposed that aligned to this change must come a reappraisal of both the soundscape and how listening processes are traditionally defined, in order to account for increasing information complexity within ambient information environments. At this point, historical 'Ambient Music' seems increasingly divergent from day-to-day experience and how we perceive an information-dense world. Listening and writing about soundscape as an object must give way to understanding ambient environments as an embodied experience. Space in the ambience today is personal. 
MUSIC BEYOND AIRPORTS 